\title{
DFT Study of the effects of counter ions on bonding, molecular and spectral properties of pentaflourophenyl xenonium diflouride cation
}

\author{
HOSSEIN TAVAKOL* and NEDA KHEDRI \\ Department of Chemistry, Isfahan University of Technology, Isfahan, 84156-83111, Iran \\ e-mail: H_tavakol@cc.iut.ac.ir; hosein_ta@yahoo.com
}

MS received 4 September 2014; revised 26 June 2015; accepted 2 July 2015

\begin{abstract}
The structures and properties of pentaflourophenyl xenonium diflouride cation (PFF) have been studied in their salts with 12 different counter ions using DFT calculations. The results demonstrated the huge effect of counter ion on all properties. The hybridization values, obtained from the NBO calculations, showed that xenon mostly used pure $\mathrm{p}$ orbital in their bonds, especially in Xe-F bond. Calculated binding energies $\left(\Delta \mathrm{H}_{\mathrm{b}}\right)$ and $\left.\Delta \mathrm{G}_{\mathrm{b}}\right)$ indicated that the best anions for $\mathrm{PFF}$ are $\mathrm{OH}, \overline{\mathrm{F}}, \mathrm{BH}_{4}$ and $\mathrm{OAc}^{-}$. Moreover, the variations of HOMO and LUMO energies and the reactivity parameters have been investigated for all structures. The results of QTAIM calculations confirmed the covalent nature of $\mathrm{Xe}-\mathrm{C}$ bond and the electrostatic nature of other xenon bonds. Finally, IR frequencies, NMR chemical shifts and NMR coupling constants were calculated to examine the effect of counter ion on the spectral properties of studied structures.
\end{abstract}

Keywords. Organoxenon; DFT; counter ion; xenonium difluoride; bonding.

\section{Introduction}

Despite the opinion of pioneer chemists about the unreactivity of noble gases, since $1962^{1}$ (based on the report of Bartlett), it has been accepted that they could react and make stable molecules. After the first synthesis of a compound from the noble gas, a large number of chemists have been interested on this subject and many studies have been performed on the experimental and theoretical investigation of noble gas compounds., ${ }^{2,3}$ Among various noble gases, less attention has been made on the first two noble gases, helium and neon and some studies have been focused on the chemistry of $\operatorname{argon}^{4-6}$ and krypton. ${ }^{7-10}$ Since preparation, isolation and study of noble gas compounds are difficult, theoretical methods have been mostly used to anticipate the bonding, ${ }^{11,12}$ formation ${ }^{13}$ and properties ${ }^{14,15}$ of these compounds. Some investigations have been focused on the theoretical study of all noble gases without considering a special noble gas. ${ }^{16-23}$ However, xenon-containing molecules have been mostly studied using theoretical and experimental methods because xenon has more reactivity than the other noble gases and its compounds are more stable than compounds of other noble gases. ${ }^{24}$ Theoretical studies have also been of interest because many aspects of these materials can-

*For correspondence not be studied by experimental tools. Therefore, some reports have been published on the theoretical study of $\mathrm{HXeOX},{ }^{25} \mathrm{XeH}_{2},{ }^{26}$ xenon-nitrogen compounds, ${ }^{27}$ $\mathrm{HXeBr},{ }^{28}$ and halogenated xenon cyanides. ${ }^{29}$

Among various xenon compounds, organoxenons have been attracted more attentions after the preparation of the first organoxenon, pentafluorophenylxenon $\left(\mathrm{C}_{6} \mathrm{~F}_{5} \mathrm{Xe}^{+}\right)$salts by the reaction of $\left(\mathrm{C}_{6} \mathrm{~F}_{5}\right)_{3} \mathrm{~B}$ with $\mathrm{XeF}_{2}$ in $1989 .{ }^{30,31}$ In this category, some organoxenons have been prepared such as diarylxenon, ${ }^{32}$ polyfluoroalk1-enylxenon salts $(\mathrm{RCF}=\mathrm{CRXe}+),{ }^{33-35}$ trifluoropropynyl xenon (II) tetrafluoroborate $\left(\mathrm{CF}_{3} \mathrm{CCXe}_{\mathrm{BF}}\right)^{36,37}$ and $\left[\mathrm{C}_{6} \mathrm{~F}_{5} \mathrm{XeF}_{2}\right]\left[\mathrm{BF}_{4}\right]$, which has been fully investigated recently. ${ }^{38}$ In addition, the preparation and reactivity of compounds containing a carbon-xenon bond have been reviewed by Frohn. ${ }^{39}$ Contrary to the large number of experimental and theoretical studies on organoxenons, ${ }^{40-49}$ many potential molecules and their properties in this area are also unknown and research on the new organoxenon compounds seems to be interesting. One of them is the effect of counter ions on the stabilities and properties of organoxenon cations. Therefore, to pursue our recent studies on computational chemistry of chemical structure $\mathrm{s}^{50-52}$ and study of noble gas compounds, ${ }^{53}$ we have decided to focus on the bonding, spectral and molecular properties of new organoxenon compounds.

In this work, pentaflourophenyl xenonium diflouride $\left(\mathrm{C}_{6} \mathrm{~F}_{5}-\mathrm{XeF}_{2}^{+}, \mathrm{PFF}\right)$ cation and their salts with various 
counter ion have been selected to study their properties. This cation was similar to pentafluorophenylxenon cation $\left(\mathrm{C}_{6} \mathrm{~F}_{5} \mathrm{Xe}^{+}\right),{ }^{30,31}$ the first prepared organoxenon. Pentafluorophenyl xenonium could be prepared from $\mathrm{XeF}_{2}$ while PFF could be prepared from $\mathrm{XeF}_{4}$ and the preparation of this compound with $\mathrm{BF}_{4}{ }_{4}^{-}$as counter ion has been reported by Frohn. ${ }^{38,54}$ This compound could be considered as a potential organoxenon molecule in future. Therefore, the structures of PFF alone and in the presence of 12 different anions $\left(\mathrm{F}^{-}, \mathrm{Cl}^{-}, \mathrm{Br}^{-}, \mathrm{I}^{-}, \mathrm{AsF}_{6}^{-}\right.$, $\mathrm{BF}_{4}^{-}, \mathrm{BH}_{4}^{-}, \mathrm{CH}_{3} \mathrm{COO}^{-}, \mathrm{CF}_{3} \mathrm{COO}^{-}, \mathrm{NO}_{3}^{-}, \mathrm{OH}^{-}, \mathrm{PF}_{6}^{-}$) have been optimized. Then, the bonding properties, structural parameters and vibrational frequencies of these molecules have been calculated. The atomic charges, hybridizations and second order perturbation energies of them were obtained using NBO calculations. Finally, AIM and NMR calculations were done to obtain their bonding properties and chemical shifts. The details of computations and the results are presented in the following sections.

\section{Computational}

Gaussian 09 program package ${ }^{55}$ has been employed to perform all calculations. The calculations have been carried out using density functional theory by employing B3LYP method. ${ }^{56,57}$ The B3LYP method has been validated to give results similar to those of the more computationally expensive methods for molecular geometry and frequency calculations. ${ }^{58,59}$ In combination with this method, triple-zeta Dunning's correlation consistent basis set ${ }^{60}$ augmented with diffuse function (aug-cc-pVTZ) was used for all atom except xenon and iodine. This basis set is usually used for high precision calculations and its redundant functions have been removed and rotated in order to increase computational efficiency. ${ }^{61}$ For xenon and iodine, 3-21G and LanL2DZ basis sets were employed because aug-ccpVTZ basis set could not be used on the atoms in $5^{\text {th }}$ row of periodic table. However, LanL2DZ basis set calculations produced odd results and very strange adsorption energies. Therefore, the results of calculations with LanL2DZ (for xenon and iodine) have not been considered in this manuscript and in all cases, 3-21G basis set has been employed for xenon and iodine. In addition, one series of single point calculations were performed using the same basis set at M062X method as a modern and more reliable DFT method and the results were employed in the calculation of bonding energies.

In each optimization process, the absence of imaginary frequency verified that structure was a true minimum. The results of frequency calculations were used after applying an appropriate scaling factor ( 0.971 for the employed method). ${ }^{62}$ NMR chemical shifts were obtained from the Gauge-Independent Atomic Orbital (GIAO) method. ${ }^{63} \mathrm{NBO}$ analysis of all structures have been done using $\mathrm{NBO}^{64}$ program as implemented in the Gaussian program package. NBO calculations are useful tools to calculate molecular properties such as atomic charges, atomic hybridizations and the interactions between orbitals (second-order perturbation energies) with high precision. QTAIM analyses were performed using AIM2000 program. ${ }^{65}$ Finally, the chemical potentials $(\mu)$, chemical hardnesses $(\eta)$, global softnesses $(S)$ and electrophilicity indexes $(\omega)$ of all compounds have been calculated as defined in equations 1-4 according to Koopman's theorem. ${ }^{66,67}$

$$
\begin{aligned}
& \mu=\left(\mathrm{E}_{\mathrm{LUMO}}+\mathrm{E}_{\mathrm{HOMO}}\right) / 2 \\
& \eta=\left(\mathrm{E}_{\mathrm{LUMO}}-\mathrm{E}_{\mathrm{HOMO}}\right) / 2
\end{aligned}
$$

$$
\mathrm{S}=1 / \eta
$$

$$
\omega=\mu^{2} / 2 \eta
$$

\section{Results and Discussions}

\subsection{Structural parameters and dipole moments}

All structures have been optimized to extract their parameters and used in subsequent calculations. It should be mentioned that the structural study of these molecules is an important topic in chemistry, where the cation is fixed and the anion is changed to study the effect of anion on its structure.

In this report, the only structural parameters (other data to be discussed in subsequent sections) consisting of xenon atom have been reported. It is accepted that by changing the anion from fluoride to iodide, the shape of the crystal, symmetry group, density, electrostatic interactions, hydrogen bonding, melting point, color, solubility and many other specifications of salts could be changed. The optimized structures of all PFF-anions are depicted in figure 1 , the most important structural parameters of all molecules are listed in table 1 and the general numbering scheme for all structures are shown in figure 2. In table 1, the experimental values of PFF$\mathrm{BF}_{4}$ that have also been reported ${ }^{38}$ that showed small differences with our calculated values.

Xenon is connected to two fluorine atoms in cation (PFF). The deviated T-shape of PFF- $\mathrm{XeF}_{2}$ have been proven by previous reports. ${ }^{38,54}$ The lengths of these 


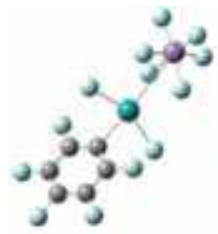

$\mathrm{PFF}-\mathrm{AsF}_{6}$

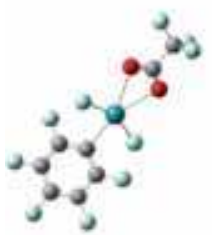

$\mathrm{PFF}-\mathrm{CF}_{3} \mathrm{COO}$

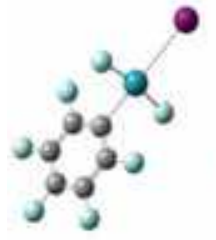

PFF-I

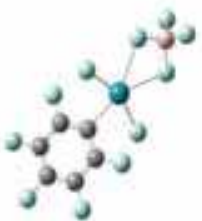

$\mathrm{PFF}_{-\mathrm{BF}_{4}}$

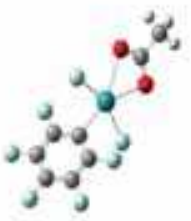

$\mathrm{PFF}-\mathrm{CH}_{3} \mathrm{COO} \quad \mathrm{PFF}-\mathrm{Cl}$

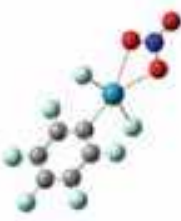

$\mathrm{PFF}-\mathrm{NO}_{3}$

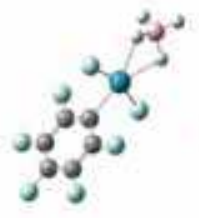

$\mathrm{PFF}_{-} \mathrm{BH}_{4}$
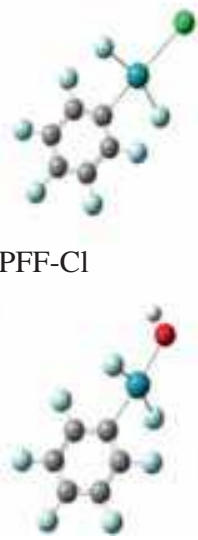

PFF-OH

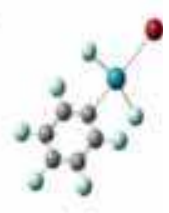

PFF-Br

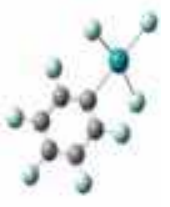

PFF-F

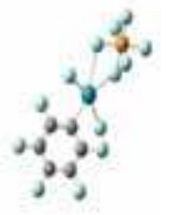

PFF-PF $_{6}$
Figure 1. Graphical representation of optimized structures of all molecules.

two bonds in each molecule except PFF-OH and PFF$\mathrm{PF}_{6}$ are the same. In $\mathrm{PFF}-\mathrm{PF}_{6}$, the difference was small (only 0.003 Á) while in PFF-OH, the Xe-F bond, which was closer to $\mathrm{OH}$ group, was $0.066 \AA$ smaller than the other Xe-F bond, probably because of a weak intramolecular hydrogen bonding. More importantly, the lengths of Xe-F bonds were affected by

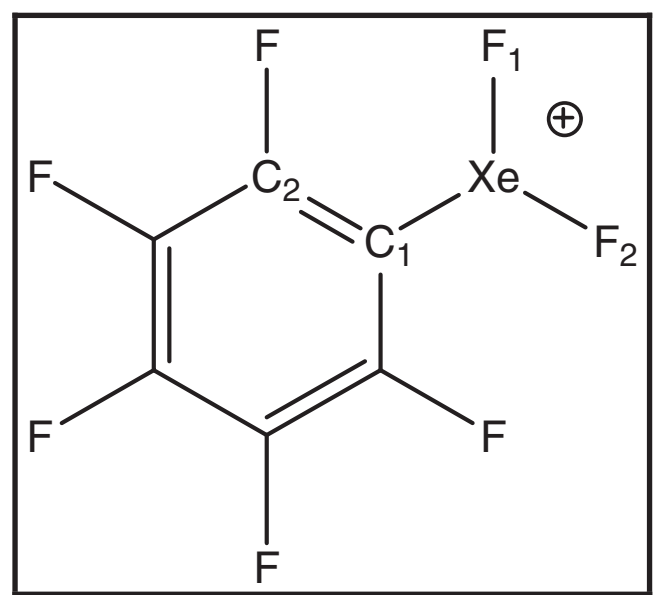

Figure 2. The numbering scheme for all structures.

the anion and their values lied between 1.982-2.118 Á. The length of Xe-F bond in PFF alone (1.944 $⿱$ Á) is smaller than that in all molecules, showing that the interaction of xenon with anion was a motive to decrease the strength and increase the length of $\mathrm{Xe}-\mathrm{F}$ bonds. The order of Xe-F bond lengths in various counter ions in these molecules was found to be: $\mathrm{F}^{-}>\mathrm{CH}_{3} \mathrm{COO}^{-}>\mathrm{CF}_{3} \mathrm{COO}^{-}>\mathrm{BF}_{4}^{-}>\mathrm{AsF}_{6}^{-}$, $\mathrm{PF}_{6}^{-}>\mathrm{BH}_{4}^{-}>\mathrm{I}^{-}>\mathrm{NO}_{3}^{-}>\mathrm{OH}^{-}>\mathrm{Br}^{-}>\mathrm{Cl}^{-}$. This order has direct relation to the strength of the interaction between PFF and counter ion. These variations showed that different anions have different interactions with PFF and the amount of these interactions are related to the electronic and spatial effects of counter ion. The first rank of fluoride showed the strongest interaction

Table 1. Optimized structural parameters and dipole moments for all structures. Bond lengths (R) are in $\AA$ and bond angles (A) and dihedral angles (D) are in degrees.

\begin{tabular}{lllllllllll}
\hline & Xe-F1 & Xe-F2 & Xe-C1 & Xe-A $^{\mathrm{a}}$ & Xe-A $^{\mathrm{b}}$ & F1-Xe-F2 & F1-Xe-C1 & C1-Xe-F2 & F1-Xe-C1-C2 & dipole \\
\hline PFF & 1.944 & 1.944 & 1.973 & - & - & 176.6 & 88.3 & 88.3 & 79.0 & 2.16 \\
PFF-AsF $_{6}$ & 2.064 & 2.064 & 2.128 & 2.568 & 3.486 & 154.1 & 77.0 & 77.1 & 52.1 & 10.28 \\
PFF-BF $_{4}$ & 2.071 & 2.071 & 2.138 & 2.522 & 3.203 & 153.7 & 76.9 & 76.8 & 51.0 & 9.92 \\
PFF-BF $_{4}($ exp) & 1.948 & 1.925 & 2.058 & 2.937 & 3.073 & 170.2 & 84.0 & 86.3 & - & - \\
PFF-BH $_{4}$ & 2.004 & 2.004 & 2.060 & 2.185 & 2.655 & 160.2 & 80.1 & 80.1 & 90.2 & 4.45 \\
PFF-Br $_{\text {PFF-CF }}$ COO & 1.968 & 1.968 & 2.147 & 2.948 & 2.948 & 161.0 & 80.5 & 80.5 & 52.3 & 5.11 \\
PFF-CH $_{3}$ COO & 2.099 & 2.078 & 2.192 & 2.575 & 2.915 & 153.2 & 76.6 & 76.6 & 50.5 & 4.44 \\
PFF-Cl $_{\text {PFF-F }}$ & 1.963 & 1.963 & 2.206 & 2.519 & 2.897 & 151.6 & 75.8 & 75.8 & 52.1 & 0.81 \\
PFF-I $_{\text {PFF-NO }}$ & 2.118 & 2.118 & 2.214 & 2.1630 & 2.830 & 159.9 & 80.0 & 80.0 & 52.8 & 5.89 \\
PFF-OH $_{\text {PFF-PF }}$ & 1.999 & 1.999 & 2.086 & 3.063 & 3.063 & 164.5 & 82.3 & 82.3 & 62.3 & 3.80 \\
& 1.992 & 1.992 & 2.027 & 2.484 & 2.920 & 157.9 & 84.5 & 84.5 & 78.4 & 4.49 \\
\hline
\end{tabular}

\footnotetext{
a The distance to the Closest atom of anion

$\mathrm{b}$ The distance to the central atom of anion

c According to reference 38
} 
between PFF and counter ion and it could be related to the highest electronegativity of fluorine; while the chloride (also has high electronegativity) had the weakest interaction with PFF. This showed that electrostatic interactions were not the sole interaction between ions and other possibilities such as polarizability (of electron clouds) and the size of anion should be considered. The order of $\mathrm{Xe}-\mathrm{C} 1$ bond length, despite some similarity with that for the Xe-F bond, showed some differences, thereby confirming the complexity of the nature of these interactions. This order of $\mathrm{Xe}-\mathrm{C}$ bond was found to be: $\mathrm{F}^{-}>\mathrm{CH}_{3} \mathrm{COO}^{-}>\mathrm{CF}_{3} \mathrm{COO}^{-}>\mathrm{Br}^{-}>\mathrm{BF}_{4}^{-}>\mathrm{AsF}_{6}^{-}>$ $\mathrm{PF}_{6}^{-}>\mathrm{Cl}^{-}>\mathrm{I}^{-}>\mathrm{OH}^{-}>\mathrm{BH}_{4}^{-}>\mathrm{NO}_{3}^{-}$. This order is more logical because the $\mathrm{Xe}-\mathrm{C}$ bond was placed exactly in the opposite side of the counter ion. In the next column, the distances between xenon and the closest atom of anion (Xe-A) and the central atom of anion (Xe-A) were reported. These values are mostly dependent on the size of counter ion. The largest Xe-A value belonged to PFF-I and the largest $\mathrm{Xe}-\mathrm{A}$ values were related to

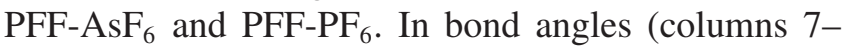
9), the values of F1-Xe-F2, C1-Xe-F and C1-Xe-F2 angles tended to be smaller in salts versus the PFF alone because of the existence of counter ions and the value of this difference were directly related to the size of counter ion. The F1-Xe-C1-C2 dihedral angle showed the amount of deviation from the planar structure of PFF. These values for PFF are equal to 79.0 degrees and in salts, they are between 50.0-90.2 degrees. Therefore, by changing the counter ion, the interaction of Xe-F bonds with benzene ring and related dihedral angle will be changed.

In the last column, the dipole moment of the molecules (in Debye) was reported. Since the large positive bar (2.136, according to table 2) was placed on xenon atom, the dipole moment of PFF was directed toward the benzene ring. Therefore, when the electronegativity of the counter ion increases, it attracted the electron density from the ring and decreases the dipole moment (PFF-OH: 1.87, PFF-OAc: 0.81). However, when the anion consisted of many electronegative atoms $\left(\mathrm{PF}_{6}^{-}\right.$and $\left.\mathrm{AsF}_{6}^{-}\right)$, the high dipole moment toward the anion could be observed. This means that the directions of dipole moments in different molecules are not the same.

\subsection{NBO analyses}

Atomic charges and hybridizations, obtained from the NBO calculations, are listed in table 2 . The values of xenon positive charges were decreased in salts versus the cation. It seems that the amount of this decrease was directly related to the softness of the anion and inversely related to its electronegativity. The smallest xenon charges were respectively related to PFF-I, PFF$\mathrm{CH}_{3} \mathrm{COO}$, PFF- $\mathrm{CF}_{3} \mathrm{COO}$ and PFF-Br while the highest xenon positive charges belonged to $\mathrm{PFF}-\mathrm{OH}$ and PFF- $\mathrm{NO}_{3}$. A different relation could be observed in the charges of fluorine atoms connected to the xenon. The maximum negative charges on fluorines belonged to $\mathrm{PFF}_{-\mathrm{BH}_{4}}, \mathrm{PFF}^{-\mathrm{NO}_{3}}$, PFF-I and PFF-OH.

Many factors should be considered to explain these charges. In the fifth column of the data, the net charges of the anions did not exceed -0.867 and in many cases, these charges were less than -0.685 . These values demonstrated that a sizable amount of the electron density of anion sank toward PFF cation. This electron transfer obviously has direct effect on the properties of the cation. The other proof for this claim is related to changing the hybridization of xenon atom in its bond with $\mathrm{C} 1$ in different molecules (columns $6,7)$. It should be first explained that our calculations confirmed that xenon mostly used its $\mathrm{p}$ orbital (without hybridization) in the bond with fluorine atoms (99.82-100 percent of its orbitals in Xe-F bonds were pure $\mathrm{p}$ orbital). Therefore, xenon only used hybridized orbitals in bonding with $\mathrm{C} 1$. The value of $\mathrm{p}$ orbital percentage that xenon atom used in $\mathrm{Xe}-\mathrm{C} 1$ bonds varied from $82.17 \%$ (in PFF) to $97.19 \%$ (in PFF-F). In PFF cation, xenon was mostly hybridized because it lost one electron and tended to make a more effective bond. These values will be confirmed by the $\mathrm{Xe}-\mathrm{C} 1$ bond lengths. According to our data, the least value (and the most bond strength) belonged to PFF cation. In other molecules (PFF and anion), the $\mathrm{p}$ orbital percentages were larger than $90.27 \%$. The highest $\mathrm{p}$ orbital percentages belonged to PFF-F and PFF-OH, which consisted of the most electron-withdrawing anions. Since the increase of $\mathrm{p}$ orbital contribution was related to the decrease of the bond strength, it could be concluded that electron-withdrawing anions made the $\mathrm{Xe}-\mathrm{C}$ bond weaker because this bond was placed in the opposite side of Xe-anion connection.

\subsection{Energies and stabilities}

It is important to obtain energy and stability information, especially when we encounter noble gas molecules. In this line, the effect of counter ion on the stability of salts seems to be important. Table 3 shows calculated binding energies (in $\mathrm{kcal} / \mathrm{mol}$ ) between PFF and various anions obtained from both B3LYP and M062X methods using 3-21G basis set for xenon and iodine and aug-cc-pVTZ basis set for other atoms. The 
Table 2. Atomic charges (in atomic units) and hybridizations (in percent) obtained from NBO calculations.

\begin{tabular}{|c|c|c|c|c|c|c|c|}
\hline \multirow[b]{2}{*}{ charges } & \multicolumn{5}{|c|}{ Atomic charges } & \multicolumn{2}{|c|}{ Hybridizations $^{\mathrm{a}}$} \\
\hline & $\mathrm{Xe}$ & $\mathrm{F} 1$ & $\mathrm{~F} 2$ & $\mathrm{C} 1$ & A & $\mathrm{Xe}$ in $\mathrm{Xe}-\mathrm{C} 1$ & $\mathrm{Xe}$ in $\mathrm{Xe}-\mathrm{F}$ \\
\hline PFF & 2.136 & -0.588 & -0.588 & -0.432 & & 82.17 & \\
\hline PFF-AsF 6 & 2.062 & -0.560 & -0.560 & -0.290 & -0.865 & 90.41 & 99.82 \\
\hline $\mathrm{PFF}-\mathrm{BF}_{4}$ & 2.045 & -0.562 & -0.562 & -0.293 & -0.829 & 91.18 & 99.84 \\
\hline PFF-BH 4 & 2.050 & -0.620 & -0.620 & -0.391 & -0.578 & 93.62 & \\
\hline PFF-Br & 1.982 & -0.604 & -0.604 & -0.357 & -0.538 & 92.38 & \\
\hline $\mathrm{PFF}-\mathrm{CF}_{3} \mathrm{COO}$ & 1.936 & -0.580 & -0.580 & -0.279 & -0.632 & 93.23 & 99.82 \\
\hline $\mathrm{PFF}-\mathrm{CH}_{3} \mathrm{COO}$ & 1.920 & -0.593 & -0.593 & -0.278 & -0.547 & 94.51 & 99.83 \\
\hline $\mathrm{PFF}-\mathrm{Cl}$ & 2.035 & -0.603 & -0.603 & -0.363 & -0.605 & 91.91 & \\
\hline PFF-F & 2.010 & -0.567 & -0.567 & -0.333 & -0.652 & 97.19 & 99.87 \\
\hline PFF-I & 1.911 & -0.614 & -0.614 & -0.424 & -0.409 & 92.26 & \\
\hline $\mathrm{PFF}-\mathrm{NO}_{3}$ & 2.130 & -0.619 & -0.619 & -0.401 & -0.685 & 90.57 & \\
\hline $\mathrm{PFF}-\mathrm{OH}$ & 2.135 & -0.612 & -0.648 & -0.433 & -0.566 & 96.17 & \\
\hline PFF-PF 6 & 2.059 & -0.559 & -0.558 & -0.289 & -0.867 & 90.27 & 99.82 \\
\hline
\end{tabular}

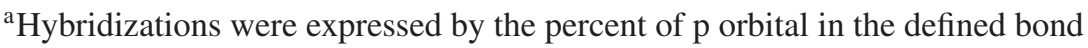

results of both methods are similar and only M062X bonding energies have tended to be more positive (between $2-8 \mathrm{kcal} / \mathrm{mol})$. Both heats of binding $\left(\Delta \mathrm{H}_{\mathrm{b}}\right)$ and Gibbs free energies of binding $\left(\Delta \mathrm{G}_{\mathrm{b}}\right)$ at standard conditions were calculated for all the molecules. Except in PFF-I, all binding energies are negative by large amounts. These values showed that counter anion made organoxenon molecules more stable (except iodide). They also proposed that in terms of interaction energies, the best anions for PFF were $\mathrm{OH}^{-}, \mathrm{F}^{-}, \mathrm{BH}_{4}^{-}$, $\mathrm{OAc}^{-}, \mathrm{Cl}^{-}, \mathrm{Br}^{-}, \mathrm{NO}_{3}^{-}, \mathrm{CF}_{3} \mathrm{COO}^{-}, \mathrm{BF}_{4}^{-}, \mathrm{PF}_{6}^{-}, \mathrm{AsF}_{6}^{-}$and $\mathrm{I}^{-}$, respectively. It is obvious that by increasing electronegativity and decreasing the size of the anion, its stabilizing effect on PFF will be increased. Therefore, it could be concluded that the electron-withdrawing anions attract the extra electron density placed on xenon atom and stabilize it while large anions increase the electron repulsion and destabilize PFF.

The other important energy entries are frontier molecular orbitals (FMOs, i.e., HOMO and LUMO) energies. The shapes of these orbitals are shown in figure 3. The HOMO and LUMO energy values could be related to the reactivity parameters, softness and hardness. Therefore, HOMO and LUMO energies, the energy gaps $(\mathrm{Eg})$, chemical potentials $(\mu)$, chemical hardnesses $(\eta)$, global softnesses (S) and electrophilicity indexes $(\omega)$ have been calculated and the results are listed in table 4. Because of the cationic nature of PFF, it was expected that the HOMO and LUMO energies of PFF would be lower than those in all neutral molecules,

Table 3. Calculated binding energies between PFF and various anions defined by heats of binding $\left(\Delta \mathrm{H}_{\mathrm{b}}\right)$ and $\mathrm{Gibbs}$ free energies of binding $\left(\Delta \mathrm{G}_{\mathrm{b}}\right.$, both in $\left.\mathrm{kcal} / \mathrm{mol}\right)$ at standard condition using 3-21G basis set for xenon and iodine and aug-ccpVTZ basis set for other atoms.

\begin{tabular}{|c|c|c|c|c|}
\hline \multirow[b]{2}{*}{ Molecule } & \multicolumn{2}{|c|}{ B3LYP calculations } & \multicolumn{2}{|c|}{ M062X calculations } \\
\hline & $\Delta \mathrm{H}_{\mathrm{b}}^{\mathrm{a}}$ & $\Delta \mathrm{G}_{\mathrm{b}}^{\mathrm{b}}$ & $\Delta \mathrm{H}_{\mathrm{b}}^{\mathrm{a}}$ & $\Delta \mathrm{G}_{\mathrm{b}}^{\mathrm{b}}$ \\
\hline PFF-AsF 6 & -80.60 & -68.89 & -78.62 & -66.81 \\
\hline${\mathrm{PFF}-B F_{4}}$ & -91.46 & -80.50 & -86.40 & -75.55 \\
\hline $\mathrm{PFF}_{-} \mathrm{BH}_{4}$ & -132.32 & -124.44 & -124.26 & -116.30 \\
\hline PFF-Br & -124.28 & -116.23 & -120.41 & -112.46 \\
\hline PFF-CF $\mathrm{CF}_{3} \mathrm{COO}$ & -109.44 & -96.90 & -106.32 & -93.68 \\
\hline PFF- $\mathrm{CH}_{3} \mathrm{COO}$ & -134.33 & -120.66 & -128.78 & -115.20 \\
\hline PFF-Cl & -127.61 & -119.22 & -122.98 & -114.49 \\
\hline PFF-F & -150.06 & -142.21 & -142.56 & -134.78 \\
\hline PFF-I & 205.46 & 211.61 & 213.20 & 218.54 \\
\hline $\mathrm{PFF}-\mathrm{NO}_{3}$ & -126.98 & -115.95 & -121.23 & -110.31 \\
\hline PFF-OH & -177.27 & -168.56 & -168.22 & -159.62 \\
\hline $\mathrm{PFF} \mathrm{PF}_{6}$ & -80.81 & -69.71 & -77.84 & -66.84 \\
\hline
\end{tabular}

${ }^{\mathrm{a}} \Delta \mathrm{H}_{\mathrm{b}}=\mathrm{H}(\mathrm{PFF}-$ Anion $)-\mathrm{H}(\mathrm{PFF})-\mathrm{H}($ anion $)$

${ }^{\mathrm{b}} \Delta \mathrm{G}_{\mathrm{b}}=\mathrm{G}($ PFF-Anion) $-\mathrm{G}(\mathrm{PFF})-\mathrm{G}$ (anion) 
LUMO
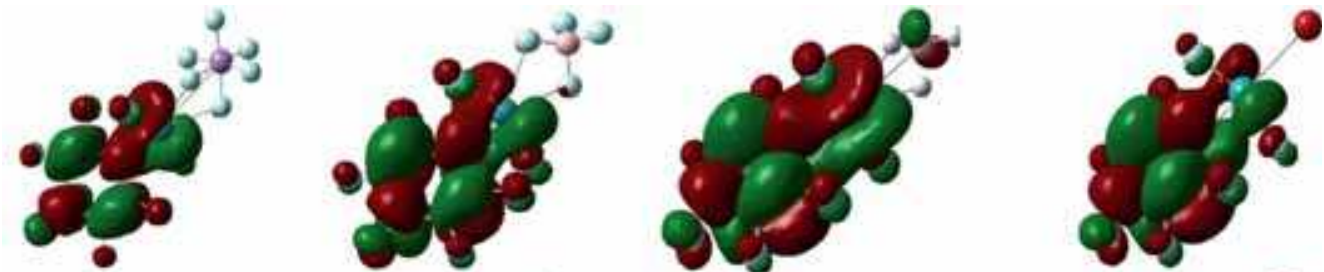

HOMO
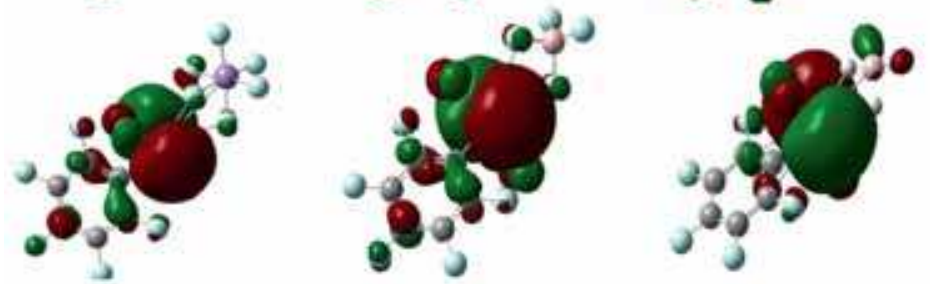

PFF-AsF 6

PFF-BF 4

PFF-BH

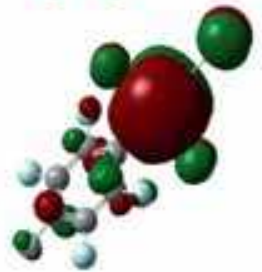

PFF-Br

LUMO
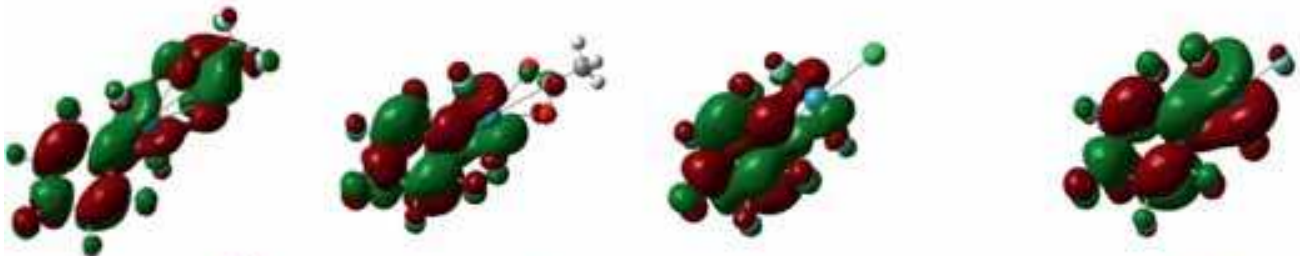

HOMO
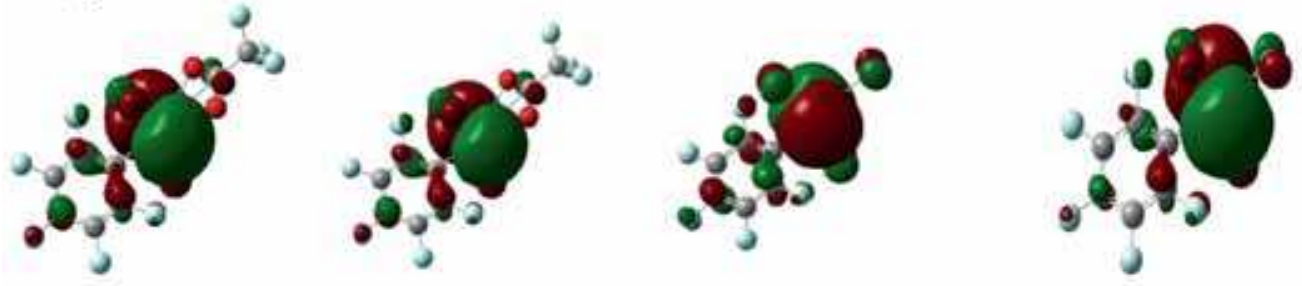

PFF- $\mathrm{CF}_{3} \mathrm{COO}$

PFF- $\mathrm{CH}_{3} \mathrm{COO}$

PFF-Cl
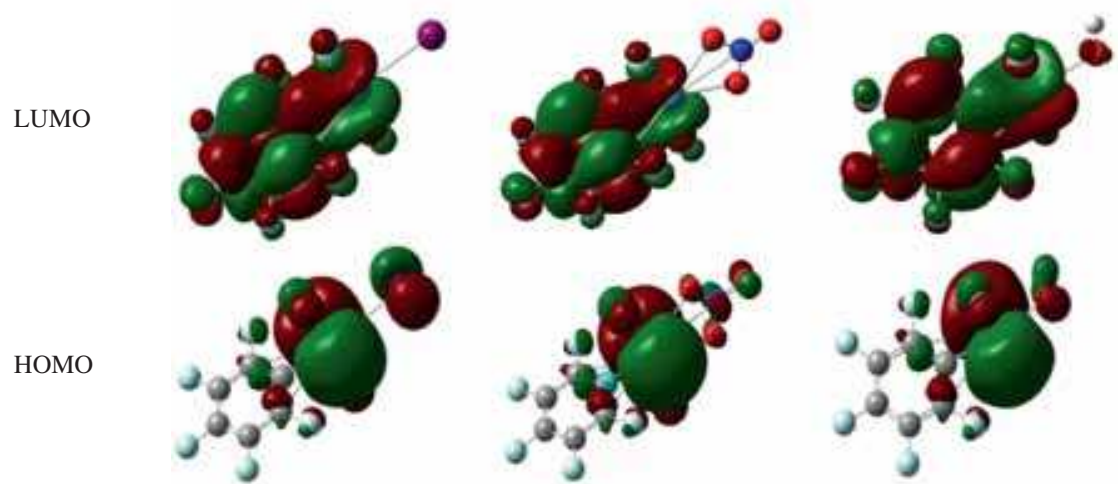

PFF-F
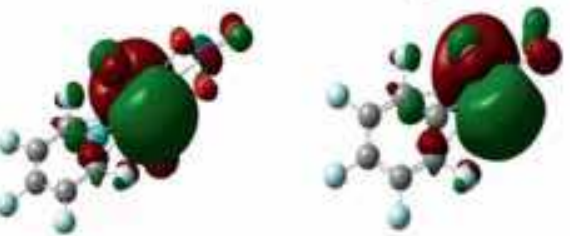

PFF-I

PFF-NO

PFF-OH
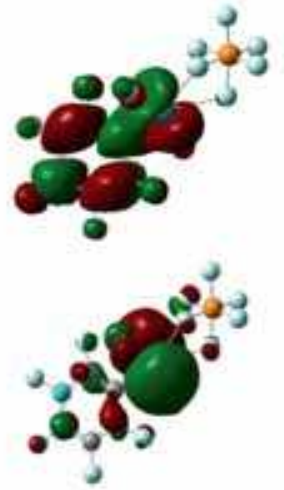

PFF-PF $_{6}$

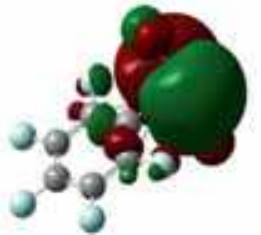

LUMO

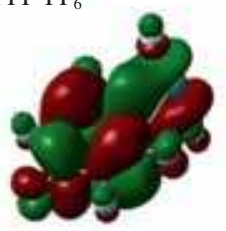

Figure 3. The graphical representation of HOMO and LUMO for all molecules.

but its energy gap was placed almost in the middle of $\mathrm{E}_{\mathrm{g}}$ for other molecules. Moreover, fluorine-containing substituents $\left(\mathrm{F}, \mathrm{CF} 3 \mathrm{COO}, \mathrm{BF}_{4}, \mathrm{AsF}_{6}\right.$ and $\mathrm{PF}_{6}$ ) obviously decreased the HOMO energy. This decrease was followed by decrease in LUMO energy and therefore, no specific change in Eg could be observed. In other columns, chemical potentials, softness, hardness and electrophilicity indexes show changes with variation of the counter ion. The chemical potentials of fluorinecontaining anions have the smallest values (the highest absolute values) while PFF-I had the highest chemical potential $(-0.206)$. Moreover, softness and hardness 
Table 4. The energies of HOMO, LUMO, band gap $\left(\mathrm{E}_{\mathrm{g}}\right)$ and reactivity parameters from population analyses.

\begin{tabular}{|c|c|c|c|c|c|c|c|}
\hline & LUMO & HOMO & $\mathrm{Eg}$ & $\mu$ & $\mathrm{H}$ & $S$ & $\omega$ \\
\hline PFF & -0.318 & -0.456 & 0.138 & -0.387 & 0.069 & 14.491 & $5.18 \mathrm{E}-03$ \\
\hline PFF-AsF 6 & -0.216 & -0.341 & 0.124 & -0.278 & 0.062 & 16.069 & $2.41 \mathrm{E}-03$ \\
\hline $\mathrm{PFF}^{-\mathrm{BF}_{4}}$ & -0.215 & -0.338 & 0.124 & -0.277 & 0.062 & 16.172 & $2.37 \mathrm{E}-03$ \\
\hline PFF-BH 4 & -0.156 & -0.308 & 0.152 & -0.232 & 0.076 & 13.158 & $2.05 \mathrm{E}-03$ \\
\hline PFF-Br & -0.163 & -0.272 & 0.109 & -0.218 & 0.054 & 18.350 & $1.29 \mathrm{E}-03$ \\
\hline $\mathrm{PFF}-\mathrm{CF}_{3} \mathrm{COO}$ & -0.192 & -0.319 & 0.127 & -0.256 & 0.063 & 15.769 & $2.07 \mathrm{E}-03$ \\
\hline $\mathrm{PFF}-\mathrm{CH}_{3} \mathrm{COO}$ & -0.173 & -0.304 & 0.131 & -0.238 & 0.065 & 15.298 & $1.85 \mathrm{E}-03$ \\
\hline PFF-Cl & -0.164 & -0.283 & 0.118 & -0.223 & 0.059 & 16.929 & $1.48 \mathrm{E}-03$ \\
\hline PFF-F & -0.205 & -0.320 & 0.115 & -0.262 & 0.058 & 17.370 & $1.98 \mathrm{E}-03$ \\
\hline PFF-I & -0.163 & -0.250 & 0.087 & -0.206 & 0.044 & 22.885 & $9.30 \mathrm{E}-04$ \\
\hline PFF-NO ${ }_{3}$ & -0.154 & -0.306 & 0.152 & -0.230 & 0.076 & 13.160 & $2.02 \mathrm{E}-03$ \\
\hline PFF-OH & -0.144 & -0.299 & 0.155 & -0.221 & 0.078 & 12.891 & $1.90 \mathrm{E}-03$ \\
\hline PFF-PF 6 & -0.219 & -0.342 & 0.123 & -0.281 & 0.062 & 16.256 & $2.42 \mathrm{E}-03$ \\
\hline
\end{tabular}

All parameters (except $\mathrm{S}$ ) have been reported in $\mathrm{eV}$. S values are in $\mathrm{eV}^{-1}$

are directly related to the size of the anion. For example, PFF-I had the minimum hardness and the maximum softness while PFF-OH had maximum hardness and minimum softness. In the last column, the order of electrophilicity indexes by various anions is shown as, $\mathrm{PF}_{6}^{-}>\mathrm{AsF}_{6}^{-}>\mathrm{BF}_{4}^{-}>\mathrm{CF}_{3} \mathrm{COO}^{-}>\mathrm{BH}_{4}^{-}>\mathrm{NO}_{3}^{-}>$ $\mathrm{F}^{-}>\mathrm{OH}^{-}>\mathrm{OAc}^{-}>\mathrm{Cl}^{-}>\mathrm{Br}^{-}>\mathrm{I}^{-}$, showing the special effect of fluorine-containing anions on the electrophilicity indexes of molecules. All of these values demonstrated that counter ions changed the reactivity parameters of molecules. In this line, fluorinecontaining anions and electron-withdrawing anions have more intense effects.

\subsection{Bonding properties from the QTAIM}

QTAIM analysis is a valuable tool to define the quality and quantity of inter- and intramolecular bonding interactions. In table 5, the $\rho$ (electronic density in $\left.\mathrm{e}^{3} / \mathrm{a}_{\mathrm{o}}^{3}\right)$ and the Laplacian of $\rho$ (in $\mathrm{e} / \mathrm{a}_{\mathrm{o}}^{5}$ ) at the bond critical points (BCPs) have been listed for Xe-C1, Xe-F1, $\mathrm{Xe}-\mathrm{F} 2$ and $\mathrm{Xe}$-anion interactions.

Because of the large electron density placed on xenon atom, all $\rho$ values are large for the $\mathrm{Xe}-\mathrm{C} 1, \mathrm{Xe}-\mathrm{F} 1$ and $\mathrm{Xe}-\mathrm{F} 2$ bonds. For Xe-C1 bond (columns 2-4), $\rho$ values are placed between $0.117-0.160$ for salts and 0.170 for PFF. It was found that the counter ion decreased the electron density of the $\mathrm{Xe}-\mathrm{C} 1$ bond. The smallest $\rho$ values were observed for fluoride and acetate anions. The $\rho$ values in Xe-F1 and X3-F2 (columns 5 and 8) were almost the same and generally smaller than those in $\mathrm{Xe}-\mathrm{C} 1$ bonds. These values are in the range of $0.0995-0.131$ for salts and 0.137 for PFF. In addition, in these bonds, the minimum $\rho$ value was observed in fluoride and acetate anions. All $\rho$ values confirmed that electron-withdrawing anions attract the electron density of xenon and reduced the corresponding $\rho$ values. The $\rho$ values between PFF and different anions (the second part of table 5) are between 0.036 (in PFF-AsF6) and 0.113 (in PFF-OH). The order of $\rho$ values between $\mathrm{PFF}$ and different anions is $\mathrm{OH}^{-}>\mathrm{F}^{-}>\mathrm{BH}_{4}^{-}>\mathrm{NO}_{3}^{-}>\mathrm{OAc}^{-}>\mathrm{CF}_{3} \mathrm{COO}^{-}>\mathrm{PF}_{6}^{-}>$ $\mathrm{Cl}^{-}>\mathrm{Br}^{-}>\mathrm{BF}_{4}^{-}>\mathrm{I}^{-}>\mathrm{AsF}_{6}^{-}$. This order confirmed the tendency of electron density towards more electronwithdrawing groups. The next parameter, Laplacian of $\rho(\mathrm{L}(\rho)=-1 / 42 \mathbf{\nabla} \rho)$, showed the nature of each bond between two atoms.

The Laplacian of $\rho$ is positive for $\mathrm{Xe}-\mathrm{C} 1$ bond and negative for Xe-F1, Xe-F2 and Xe-A bonds. This means that $\mathrm{Xe}-\mathrm{C} 1$ is a covalent bond while $\mathrm{Xe}-\mathrm{F} 1, \mathrm{Xe}-\mathrm{F} 2$ and $\mathrm{Xe}-\mathrm{A}$ are non-covalent and they have closed shell or electrostatic interaction in their bonds. These observations confirmed the NBO results regarding the electrostatic nature of Xe-F bonds. Moreover, the value of Laplacian of $\rho$ in PFF is larger than those in other molecules. The least absolute values of Laplacian of $\rho$ have been observed in electron-withdrawing and fluorine-containing anions.

\subsection{Harmonic vibrations}

The harmonic vibrational modes for all molecules were calculated using frequency calculations. The results for $\mathrm{Xe}-\mathrm{F}$ (symmetric and asymmetric), $\mathrm{Xe}-\mathrm{C} 1$ and $\mathrm{Xe}-$ A stretching vibrations are listed in table 6 in addition to the reported experimental values ${ }^{38}$ for PFF$\mathrm{BF}_{4}$. These experimental values are in agreement with our data showing the reliabilty of our calculated frequemcies. From the data listed in this table, it was found that PFF has the maximum value in each entry of frequency tables, showing that all these bonds in PFF were stronger than those in other molecules. The 
Table 5. The electron densities $(\rho)$ and the Laplacian of the electron densities $\left(\boldsymbol{L}(\boldsymbol{\rho})=-\mathbf{1} / \mathbf{4} \boldsymbol{\nabla}^{\mathbf{2}} \boldsymbol{\rho}\right)$ obtained from AIM calculations.

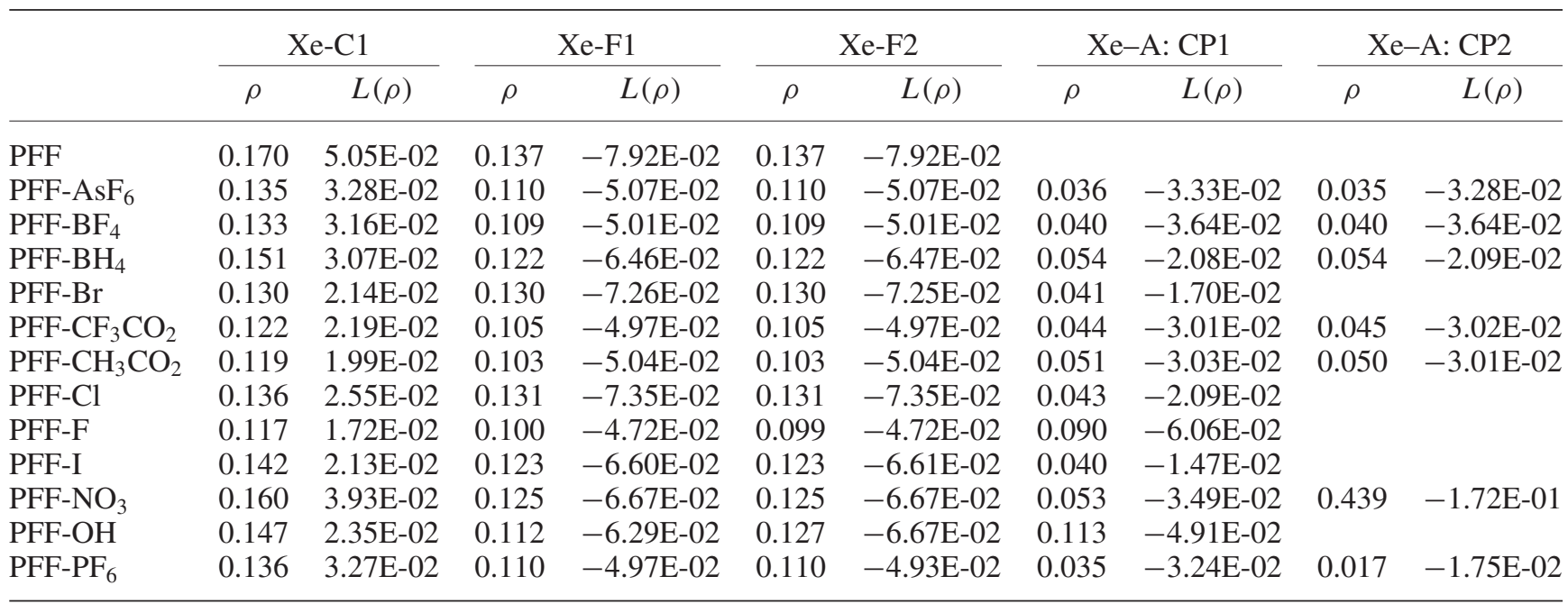

Table 6. Calculated harmonic vibrational frequencies (in $\mathrm{cm}^{-1}$ ).

\begin{tabular}{|c|c|c|c|c|}
\hline corrected & Xe-F1,2 (Asym) & Xe-F1,2 (Sym) & $\mathrm{Xe}-\mathrm{C} 1$ & $\mathrm{Xe}-\mathrm{A}$ \\
\hline PFF & 571 & 516 & 829 & \\
\hline PFF-AsF 6 & 372 & 366 & 739 & 96 \\
\hline $\mathrm{PFF}_{-\mathrm{BF}_{4}}$ & 401 & 360 & 736 & 128 \\
\hline $\mathrm{PFF} \mathrm{BF}_{4}(\exp )^{38}$ & 535 & 530 & 789 & 127 \\
\hline PFF-BH 4 & 519 & 447 & 808 & 159 \\
\hline PFF-Br & 510 & 475 & 763 & 112 \\
\hline $\mathrm{PFF}_{-} \mathrm{CF}_{3} \mathrm{COO}$ & 384 & 347 & 717 & 186 \\
\hline PFF- $\mathrm{CH}_{3} \mathrm{COO}$ & 377 & 334 & 722 & 188 \\
\hline PFF-Cl & 519 & 489 & 773 & 151 \\
\hline PFF-F & 356 & 307 & 710 & 351 \\
\hline PFF-I & 480 & 431 & 793 & 113 \\
\hline PFF-NO ${ }_{3}$ & 498 & 455 & 825 & 205 \\
\hline PFF-OH & 494 & 430 & 813 & 451 \\
\hline PFF-PF 6 & 386 & 368 & 735 & 98 \\
\hline
\end{tabular}

values of Xe-F for asymmetric vibration were between $356-519 \mathrm{~cm}^{-1}$ and for symmetric vibrations, they were between $307-489 \mathrm{~cm}^{-1}$. Since many factors can affect the frequencies, no meaningful order could be observed for these vibrations. However, the least frequency value for both cases was related to PFF-F. It is demonstrated that by increasing the strength of interaction between PFF and the counter ion, the values of xenon-related stretching vibrations were decreased. In the next column, the Xe-C stretching modes were in the range of $717-825 \mathrm{~cm}^{-1}$. These values are larger than the frequency of Xe-F bond because this bond is covalent in nature, unlike the electrostatic nature of Xe-F bond. Moreover, this frequency was useful for determining the existence of organoxenon compounds. Like Xe$\mathrm{F}$ frequencies, no meaningful relation between $\mathrm{Xe}-\mathrm{C} 1$ frequencies and the nature of counter ion could be observed.
The last frequency, Xe-A, was linked to the stretching between PFF cation and counter ion. The existence of this frequency proved the remarkable interaction between these ions and more importantly, the direct relation between the strength of this interaction and the value of stretching frequency between ions. We examined the linearity of this relation (between frequency and $\Delta \mathrm{H}_{\mathrm{b}}$ in all molecules except PFF-I) and a line $\left(\Delta \mathrm{H}_{\mathrm{b}}=-0.225 \times v(\mathrm{PFF}-\mathrm{A})-77.852\right)$ with $\mathrm{R}^{2}=0.727$ was observed. Therefore, this was not a linear relation, but it could be considered as a qualitative relation.

\subsection{NMR chemical shifts}

In the final part of this study, NMR chemical shifts (in ppm) and coupling constants (in $\mathrm{Hz}$ ) were calculated for all the molecules. The results are listed in 
table 7 and the experimental values ${ }^{54}$ for $\mathrm{PFF}_{-\mathrm{BF}_{4}}$ are also added to the table. We focused on ${ }^{129} \mathrm{Xe},{ }^{19} \mathrm{~F}$ (F1 and F2) and $\mathrm{C} 1$ chemical shifts in these calculations. The ${ }^{129} \mathrm{Xe}$ chemical shift is an interesting topic in NMR studies of xenon-containing molecules. Xenon chemical shifts were determined versus the chemical shift of $\mathrm{XeOF}_{4}$ and fluorine chemical shifts were determined versus the chemical shift of $\mathrm{CFCl}_{3}$. For ${ }^{129} \mathrm{Xe}$ and ${ }^{13} \mathrm{C}$ chemical shifts and Xe-F coupling constants, the differences between experimental and theoretical values are small. However, for ${ }^{19} \mathrm{~F}$ chemical shifts, large differences were observed. The range of xenon chemical shifts was varied from $847 \mathrm{ppm}$ in PFF-I to $2220 \mathrm{ppm}$ in PFF-NO $\mathrm{N}_{3}$ and the chemical shift of xenon in PFF was placed in the middle of this range $(1559 \mathrm{ppm})$. Oxygen-containing anions increased the xenon chemical shift evidently, while halogen-containing anions (including fluoride) decreased its chemical shift versus the PFF ( $\delta=1559 \mathrm{ppm}$ ). It seems that the strong interaction between PFF and counter ion, like the interaction observed in fluoride and fluorine-containing substituents, increases the electron density around xenon and shields it in NMR experiment.

The shorter distance between xenon and these anions (table 1) is the other proof for this claim. Unlike the xenon chemical shifts, $\mathrm{C} 1$ chemical shifts in all molecules (between 129-152 ppm) are greater than those in PFF alone (118 ppm). The acceptable explanation for this difference is the fact that for xenon chemical shift, anion has two effects; one is inductive electron withdrawing effect to reduce the shielding and the other is increasing electron density to increase the shielding. However, for $\mathrm{C} 1$ chemical shifts, the anion only had the inductive and deshielding effect on $\mathrm{C} 1$. Therefore, all electron-withdrawing anions (both oxygen and fluorine-containing anions) increased the chemical shift of $\mathrm{C} 1$. The fluorine chemical shifts (F1 and F2) had a large range, between $-120 \mathrm{ppm}$ and $117 \mathrm{ppm}$. The order of these variations for different molecules was $\mathrm{Br}^{-}>\mathrm{Cl}^{-}>\mathrm{I}^{-}>\mathrm{NO}_{3}^{-}>\mathrm{BH}_{4}^{-}>\mathrm{OH}^{-}>\mathrm{CH}_{3} \mathrm{COO}$ ${ }^{-}>\mathrm{CF}_{3} \mathrm{COO}^{-}>\mathrm{F}^{-}>\mathrm{AsF}_{6}^{-}>\mathrm{PF}_{6}^{-}>\mathrm{BF}_{4}^{-}$. This order was also interesting because fluorine- and oxygencontaining anions had the smallest chemical shift and halides (except fluorine) had the highest chemical shifts for F1 and F2. This observation was the same with xenon chemical shifts and therefore, the same argument could be assigned to explain it. In table 7, Xe$\mathrm{F} 1, \mathrm{Xe}-\mathrm{F} 2$, and $\mathrm{Xe}-\mathrm{C} 1$ coupling constants are also reported.

Interestingly, despite the identical sign of the gyromagnetic ratios of ${ }^{19} \mathrm{~F}$ and ${ }^{13} \mathrm{C}$, Xe-F coupling constants are negative while $\mathrm{Xe}-\mathrm{C}$ coupling constant are positive. Moreover, Xe-F coupling constants were greater than $\mathrm{Xe}-\mathrm{C}$ coupling constants. These differences might arise from the different nature or strength of these two bonds. The values of $\mathrm{J}_{\mathrm{Xe}-\mathrm{F}}$ in fluorine containing anions were larger than those in other molecules. However, $\mathrm{J}_{\mathrm{Xe}-\mathrm{C}}$ values were greater in halide and smaller in fluorine containing anions. All of these observations could help us to investigate new organoxenon molecules. However, in addition to the value of xenon chemical shifts, $\mathrm{Xe}-\mathrm{F}$ or $\mathrm{Xe}-\mathrm{C}$ coupling constants can give us useful

Table 7. Calculated NMR chemical shifts for all structures.

\begin{tabular}{|c|c|c|c|c|c|c|c|}
\hline & \multicolumn{4}{|c|}{ Chemical shifts versus reference ${ }^{a}$} & \multicolumn{3}{|c|}{ Coupling constants ${ }^{b}$} \\
\hline & $\mathrm{Xe}$ & $\mathrm{C} 1$ & $\mathrm{~F} 1$ & $\mathrm{~F} 2$ & $\mathrm{Xe}-\mathrm{F} 1$ & $\mathrm{Xe}-\mathrm{F} 2$ & $\mathrm{Xe}-\mathrm{C} 1$ \\
\hline PFF & 1559 & 118 & 55 & 55 & -2614 & -2614 & 252 \\
\hline PFF-AsF 6 & 1608 & 148 & -114 & -114 & -3395 & -3407 & 152 \\
\hline PFF-BF 4 & 1844 & 148 & -120 & -120 & -3338 & -3336 & 163 \\
\hline $\mathrm{PFF} \mathrm{BF}_{4}(\exp )^{\mathrm{c}}$ & 1706 & 122 & -29.5 & -29.5 & -3892 & -3892 & - \\
\hline PFF-BH 4 & 2040 & 130 & 19 & 19 & -2731 & -2732 & 347 \\
\hline PFFBr & 1293 & 138 & 116 & 117 & -2799 & -2800 & 680 \\
\hline $\mathrm{PFF}-\mathrm{CF}_{3} \mathrm{COO}$ & 2136 & 152 & -104 & -104 & -3133 & -3130 & 283 \\
\hline $\mathrm{PFF}-\mathrm{CH}_{3} \mathrm{COO}$ & 2151 & 151 & -99 & -99 & -3008 & -3008 & 309 \\
\hline PFF-Cl & 1270 & 137 & 106 & 106 & -2802 & -2803 & 579 \\
\hline PFF-F & 1181 & 145 & -110 & -110 & -3505 & -3505 & 302 \\
\hline PFF-I & 847 & 129 & 104 & 104 & -2764 & -2764 & 737 \\
\hline PFF-NO ${ }_{3}$ & 2220 & 131 & 22 & 22 & -2538 & -2538 & 290 \\
\hline PFF-OH & 1676 & 131 & -11 & 57 & -2440 & -3370 & 339 \\
\hline PFF-PF 6 & 1614 & 149 & -118 & -115 & -3430 & -3413 & 153 \\
\hline
\end{tabular}

${ }^{a}$ The reference molecule for ${ }^{19} \mathrm{~F}-\mathrm{NMR}$ is $\mathrm{CFCl}_{3}$ with chemical shift $=163.4 \mathrm{ppm}$ and for ${ }^{129} \mathrm{Xe} \mathrm{NMR}$ is $\mathrm{XeOF}_{4}$ with chemical shift $=1633.8 \mathrm{ppm}$

${ }^{\mathrm{b}}$ Gyromagnetic ratios: $\mathrm{C}=6.73 \mathrm{~F}=25.18 \mathrm{Xe}=-7.4 \times 10^{\wedge} 7 \mathrm{rad} / \mathrm{T} . \mathrm{Sec}$

${ }^{c}$ According to the reported values in reference ${ }^{54}$ 
information regarding the nature of the molecule and their binding strength. They can also suggest the best counter ion for each purpose.

\section{Conclusions}

Novel organoxenon compounds are the subject of interest in both experimental and theoretical studies. Among these molecules, pentaflourophenyl xenonium diflouride $\left(\mathrm{C}_{6} \mathrm{~F}_{5}-\mathrm{XeF}_{2}^{+}, \mathrm{PFF}\right)$ was selected in this study and their molecular properties in presence of different counter ions have been examined. DFT calculations (B3LYP and M062X methods) with aug-cc-pVTZ basis set were used for this purpose. From the calculations, optimized structures, molecular parameters and binding energies between PFF and 12 different counter ions were extracted. The $\mathrm{Xe}-\mathrm{F}$ and $\mathrm{Xe}-\mathrm{C}$ bond lengths were different in different molecules. In addition, the molecular dipole moments were more sensitive to the counter ion. NBO calculations were used to investigate the charge and hybridization in these molecules. The hybridization values showed that pure $p$ orbital of xenon mostly involved in the bonds, especially in Xe-F. The heats of binding $\left(\Delta \mathrm{H}_{\mathrm{b}}\right)$ and Gibbs free energies of binding $\left(\Delta \mathrm{G}_{\mathrm{b}}\right)$ at standard conditions were calculated for all molecules. The results indicated that in terms of interaction energies, the best anions for $\mathrm{PFF}$ were $\mathrm{OH}^{-}, \mathrm{F}^{-}, \mathrm{BH}_{4}^{-}, \mathrm{OAc}^{-}, \mathrm{Cl}^{-}, \mathrm{Br}^{-}, \mathrm{NO}_{3}^{-}, \mathrm{CF}_{3} \mathrm{COO}^{-}$, $\mathrm{BF}_{4}^{-}, \mathrm{PF}_{6}^{-}, \mathrm{AsF}_{6}^{-}$and $\mathrm{I}^{-}$, respectively. Then the variation of HOMO and LUMO energies and the reactivity parameters versus different counter ions were examined. Further, bonding properties have been studied using QTAIM calculations and the results demonstrated the important difference in the electron densities of different salts. In addition, the sign of Laplacian of electron densities confirmed the covalent nature of Xe-C bond and the electrostatic nature of other xenon bonds. Finally, harmonic vibrations, NMR chemical shifts and NMR coupling constants have been calculated. These values could be used as useful tools to prove and examine the existence and nature of new organoxenon molecules.

\section{Acknowledgments}

We are grateful from National High-Performance Computing Center (NHPCC) at Isfahan University of Technology (http://nhpcc.iut.ac.ir, Rakhsh supercomputer) for providing computational facilities to perform this work. This work was supported by the research affairs of Isfahan Univerity of technology.

\section{References}

1. Bertlett N 1962 Proc. Chem. Soc. 112218

2. Pettersson M, Lundell J, Khriachtchev L and Rasanen M J 1998 Chem. Phys. 109618

3. Dixon D A, Peterson K A, Christe K O and Schrobilgen G J 2005 J. Am. Chem. Soc. 1278627

4. Chenga C, Shenga L and Li Z S 2012 Mol. Phys. 110 293

5. Sheng L, Cohen A and Gerber R B 2006 J. Am. Chem. Soc. 1287156

6. Huang Z, Guo L, Shen T, Ma L and Niu X 2012 Phys. Chem. Chem. Phys. 148083

7. Khriachtchev L, Tanskanen H, Cohen A, Gerber R B, Lundell J, Pettersson M, Kiljunen $\mathrm{H}$ and Räsänen $\mathrm{M}$ 2003 J. Am. Chem. Soc. 1256876

8. Tanskanen H, Khriachtchev L, Lundell J, Kiljunen H and Räsänen M 2003 J. Am. Chem. Soc. 12516361

9. Lundell J, Khriachtchev L, Pettersson $M$ and Räsänen M 2003 Phys. Chem. Chem. Phys. 53334

10. Chaban G M 2004 Chem. Phys. Lett. 395182

11. Rodrigues E F F, Desa E L and Haiduke R L A $2010 \mathrm{~J}$. Phys. Chem. A 1145222

12. Bertolus M, Majora M and Brenner V 2012 Phys. Chem. Chem. Phys. 14553

13. Brock D S, Bilir V, lene H, Mercier P A and Schrobilgen G J 2007 J. Am. Chem. Soc. 1293598

14. Muck L A, Timoshkin A Y, Hopffgarten M V and Frenking G 2009 J. Am. Chem. Soc. 1313942

15. Breckenridge W H, Ayles V L and Wright T G 2007 Chem. Phys. 33377

16. Cukras J, Antusek R, Holka F and Sadlej J 2009 Chem. Phys. Lett. 474258

17. Borocci S, Bronzolino N and Grinetti F 2008 Chem. Phys. Lett. 45848

18. Bucinsky L, Biskupic S, Ilcin M, Lukes V and Laurinci V 2010 J. Comp. Chem. 32356

19. Belpassi L, Infante I, Tarantelli F and Visscher L 2008 J. Am. Chem. Soc. 1301048

20. Scar C, Jimnez-Halla C, Fernndez I and Frenking G 2009 Angew. Chem. Int. Ed. 48366

21. Avramopoulos A, Serrano-res L, Li J and Papadopoulos M G 2010 J. Chem. Theor. Comput. 63365

22. Pakhira S and Das A K 2011 Theor. Chem. Acc. 13095

23. Beyhan S M, Götz W, Jacob C R and Visscher L 2010 J. Chem. Phys. 13244114

24. Haner J and Schrobilgen G J 2011 Chem. Rev. 1151255

25. Jayasekharan T and Ghanty T K 2006 J. Chem. Phys. 124164309

26. Takayanagi T, Asakura T, Takahashi K, Taketsugu Y, Taketsugu T and Noro T 2007 Chem. Phys. Lett. 44614

27. Operti L, Rabezzana R, Turco F, Borocci S, Giordani M and Grinetti F 2011 Chem. Eur. J. 1710682

28. Tsuge M, Berski S, Stachowski R, Räsänen M, Latajka $\mathrm{Z}$ and Khriachtchev L 2012 J. Phys. Chem. A 1164510

29. Arppe T, Khriachtchev L, Lignell A, Domanskaya A V and Räsänen M 2012 Inorg. Chem. 514398

30. Naumann D and Tyrra W 1989 J. Chem. Soc. Chem. Commun. 47

31. Frohn H J and Jakobs S 1989 J. Chem. Soc. Chem. Commun. 625

32. Frohn H J and Theissen M 2004 J. Fluorine. Chem. 125 981 
33. Frohn H J, Adonin N Y and Bardin V V 2003 Z. Anorg. Allg. Chem. 6292499

34. Frohn H J and Bardin V V 2003 Z. Anorg. Allg. Chem 6292465

35. Frohn H J and Bardin V V 2004 Z. Anorg. Allg. Chem 6301022

36. Frohn H J and Bardin V V 2003 Chem. Commun. 2352

37. Frohn H J and Bardin V V 2006 Eur. J. Inorg. Chem. 3948

38. Koppe K, Haner J, Mercier H P A, Frohn H J and Schrobilgen G J 2014 Inorg. Chem. 5311640

39. Frohn H J and Bardin V V 2001 Organometallics 20 4750

40. Papakondylis A, Kerkines I S K and Mavridis A $2004 \mathrm{~J}$. Phys. Chem. A 10811127

41. Khriachtchev L, Domanskaya A, Lundell J, Akimov A, Rasanen M and Misochko E 2010 J. Phys. Chem. A 114 4181

42. Khriachtchev L, Lignell A, Tanskanen H, Lundell J, Kiljunen H and Rasanen M 2006 J. Phys. Chem. A 110 11876

43. Bertolus M, Majora M and Brenner V 2012 Phys. Chem. Chem. Phys. 14553

44. Bil A and Morrison C A 2012 J. Phys. Chem. A 116 3413

45. Yockel S, Gawlik E and Wilson A K 2007 J. Phys. Chem. A 11111261

46. Bardin V V and Frohn H J 2013 J. Fluorine Chem. 146 98

47. Frohn H J, Bilir V and Westphal U 2012 Inorg. Chem. 5111259

48. Bardin V V and Frohn H J 2012 J. Fluorine. Chem. 13828

49. Frohn H J and Bardin V V 2012 Inorg. Chem. 14583

50. Tavakol H 2009 THEOCHEM 916172

51. Tavakol H 2010 THEOCHEM 95416

52. Tavakol H 2013 J. Phys. Chem. A 316809

53. Tavakol H and Mollaei-Renani A 2014 Struct. Chem. 25 1013

54. Frohn H J, LeBlond N, Lutar K and Ziemva B 2000 Angew. Chem. Int. Ed. 39391
55. Frisch M J, Trucks GW, Schlegel H B, Scuseria G E, Robb M A, Cheeseman J R, Scalmani G, Barone V, Mennucci B, Petersson G A, Nakatsuji H, Caricato M, Li X, Hratchian H P, Izmaylov A F, Bloino J, Zheng G, Sonnenberg J L, Hada M, Ehara M, Toyota K, Fukuda R, Hasegawa J, Ishida v, Nakajima T, Honda Y, Kitao O, Nakai H, Vreven T, Montgomery J A, Peralta J E, Ogliaro F, Bearpark M, Heyd J J, Brothers E, Kudin K N, Staroverov V N, Kobayashi R, Normand J, Raghavachari K, Rendell A, Burant J C, Iyengar S S, Tomasi J, Cossi M, Rega N, Millam J M, Klene M, Knox J E, Cross J B, Bakken V, Adamo C, Jaramillo J, Gomperts R, Stratmann R E, Yazyev O, Austin A J, Cammi R, Pomelli C, Ochterski J W, Martin R L, Morokuma K, Zakrzewski V G, Voth G A, Salvador P, Dannenberg J J, Dapprich S, Daniels A D, Farkas O, Foresman J B, Ortiz J V, Cioslowski J and Fox D J 2009 Gaussian 09 Revision Al (Gaussian, Inc: Wallingford CT)

56. Becke A D 1993 J. Chem. Phys. 985648

57. Lee T C, Yang W T and Parr R G 1988 Phys. Rev. B 37 785

58. Zhang I Y, Wu J and Xu X 2010 Chem. Commun. 46 3057

59. Roy T K, Carrington T and Gerber R B 2014 J. Phys. Chem. A 1186730

60. Wilson A K, Van-Mourik T and Dunning T H 1996 THEOCHEM 388339

61. Davidson E R 1996 Chem. Phys. Lett. 260514

62. Alecu I M, Zheng J, Zhao Y and Truhlar D G $2010 \mathrm{~J}$. Chem Theory Comput. 62872

63. Ruud K, Helgaker T, Bak K L, Jorgensen P and Jensen H J A 1993 J. Chem. Phys. 993847

64. Reed A E, Curtiss L A and Weinhold F 1988 Chem. Rev. 88899

65. Bieglerkonig F and Schonbohm J J 2002 J. Comp. Chem. 2320

66. Parr R G, Donnelly R A, Levy M and Palke W E 1978 J. Chem. Phys. 683801

67. Parr R G, Szentpaty L V and Liu S 1999 J. Am. Chem. Soc. 1211922 